\title{
APLIKASI SISTEM INFORMASI RAPORT ONLINE (STUDI KASUS: MI DARUL MUTA'ALLIMIEN LEUWILIANG BOGOR)
}

\author{
Fizri Ayu Wijasty¹ ${ }^{\text {; Lila Dini Utami }}{ }^{2}{\text {; } \text { Priyono }^{3} \text {; Rahmat Tri Yunandar }}^{4}$ \\ Sistem Informasi Akuntansi ${ }^{12}$ \\ Universitas Bina Sarana Informatika \\ www.bsi.ac.id \\ fizriayu0412@bsi.ac.id ${ }^{1}$; lila.ldu@bsi.ac.id ${ }^{2}$ \\ Sistem Informasi ${ }^{34}$ \\ Universitas Bina Sarana Informatika \\ www.bsi.ac.id \\ priyono.pyo@bsi.ac.id ${ }^{3}$; rahmat.rtr@bsi.ac.id ${ }^{4}$
}

\begin{abstract}
Online Report Card is the concept of manipulating student value data carried out through electronic media networks. With the aim of supporting the process of granting values to students by teachers and providing convenience to teachers in the process of calculating values through the system created. The benefits of making this application system are as evaluation material for the current system and produce fast and accurate information in helping and facilitating the grading process for each daily repetition activity until the final semester examination. The research method used is direct interview with one teacher or homeroom teacher at MI Darul Muta'allimien, observing the input activities of MI Darul Muta'allimien along with literature. While the method used in making the 2013 Online Report Card Curriculum Web-Based Information System is Waterfall, which starts with planning which must be mature, followed by a fairly long analysis process, then designing a system that will be created if the system is ready to implement periodic system maintenance. Because the system will continue to grow. This system will be used by teachers at the same MI / SD level who have implemented the 2013 curriculum. Of course, the application of this online report card information system will greatly facilitate the processing of values in the 2013 curriculum where some teachers complain about processing their grades.
\end{abstract}

Keywords: Application, Information System, Online Report Card, Assessment, School

Intisari - Raport Online merupakan konsep manipulasi data nilai siswa yang dilakukan melalui jaringan media elektronik. Dengan tujuan mendukung proses pemberian nilai terhadap siswa oleh guru dan memberikan kemudahan terhadap guru dalam proses perhitungan nilai melalui sistem yang dibuat. Manfaat pembuatan sistem aplikasi ini adalah sebagai bahan evaluasi terhadap sistem yang sedang berjalan dan menghasilkan suatu informasi yang cepat dan akurat dalam membantu dan memudahkan proses memberikan nilai pada setiap kegiatan ulangan harian hingga ujian akhir semester. Metode penelitian yang digunakan adalah dengan berwawancara langsung dengan salah satu guru atau wali kelas di MI Darul Muta'allimien, observasi terhadap kegiatan penginputan nilai MI Darul Muta'allimien beserta studi pustaka. Sedangkan metode yang digunakan dalam pembuatan Sistem Informasi Raport Online Kurikulum 2013 Berbasis Web adalah Waterfall, yang dimulai dengan perencanaan yang tentu saja harus matang, dilanjutkan dengan proses Analisa yang cukup panjang, lalu merancang sistem yang akan dibuat jika telah selesai maka sistem ini siap untuk di implementasikan, setelah implementasi tentu saja ada pemeliharaan sistem yang berkala. Karena sistem akan terus berkembang. Sistem ini akan digunakan oleh para guru di jenjang MI/SD sederajat yang telah menerapkan kurikulum 2013. Tentu saja aplikasi sitem informasi raport online ini akan sangat memudahkan dalam pengolahan nilai pada kurikulum 2013 yang dimana beberapa guru mengeluh perihal pengolahan nilainya..

Kata Kunci: Aplikasi, Sistem Informasi, Raport Online, Penilaian, Sekolah

\section{PENDAHULUAN}

Media pembelajaran dapat merupakan wahana penyalur pesan dan informasi belajar. (Muhson, 2010). Pendidikan sebagai salah satu alternatif untuk memperoleh sebuah pengetahuan. (Wisarja \& Sudarsana, 2017). Penggunaan teknologi informasi dalam suatu bidang pendidikan seperti sekolah sangat dibutuhkan untuk mengelola dan menyajikan suatu informasi, diantaranya berupa 
laporan nilai raport siswa (Budiyarto \& Rochmawati, 2016)

MI Darul Muta'allimien merupakan Yayasan pendidikan tingkat SD/MI sederajat. MI Darul Muta'allimien memiliki kendala yang dialami oleh para guru, dimana pada saat mengolah nilai raport, para guru memiliki kesulitan dalam membuat deskripsi yang tepat pada raport kurikulum 2013 sehingga tidak efiesien dalam penggunaan waktu. Selain itu masih menggunakan kertas dalam menyimpan dan menyajikan informasi nilai siswa, sehingga memakan waktu, dan rentan terhadap kesalahan dalam pengerjaannya (Sari \& Saputra, 2014). Nilai tersebut nantinya akan diberikan kepada Wali Kelas disetiap akhir semester. Karena cukup banyaknya aspek nilai yang diolah, mulai dari nilai pengetahuan, keterampilan, sikap pada setiap pertemuan untuk satu mata pelajaran. Maka, perlu dibuatkannya sistem aplikasi pengolahan nilai raport agar kemudahan, kecepatan, dan ketepatan dalam pengolahan data khususnya nilai raport (Sari \& Muhartini, 2017)

\section{BAHAN DAN METODE}

\section{Metode Pengumpulan Data}

Adapun metode pengumpulan data yang penulis gunakan dalam penyusunan penelitian ini adalah sebagai berikut:

a. Wawancara (Interview)

Dalam metode ini penulis melakukan wawancara dengan salah satu wali kelas yang ada di MI Darul Muta'allimien. Dan ada beberapa hal yang dibahas dalam wawancara tersebut yaitu dari mulai cara menggunakan sistem raport kurikulum 2013 yang masih manual hingga proses cetak raport.

b. Pengamatan (Observation)

Dalam metode ini penulis melakukan observasi langsung di MI Darul Muta'allimien. Observasi yang dilakukan adalah mengamati beberapa wali kelas yang sedang menggunakan sistem raport kurikulum 2013 secara manual dan nilai-nilai apa saja yang dicatat oleh wali kelas.

c. Studi Pustaka

Dalam metode ini penulis melakukan studi pustaka di beberapa Repository kampus-kampus di Indonesia. Salah satunya Repository yang dimiliki oleh Universitas Bina Sarana Informatika.

\section{Metode Pengembangan Software}

Dalam merode ini, penulis menggunakan metode Model Waterfall, susunannya sebagai berikut :

a. Analisis Kebutuhan Software.

Dalam proses ini ada 3 (tiga) hak akses dalam aplikasi ini, yaitu guru, wali kelas dan admin. Dimana dalam 3 (tiga) hak akses tersebut ada menu-menu yang berbeda disetiap aksesnya. Jika dalam akses guru, guru hanya dapat mengakses menu nilai dan hanya dapat memasukkan nilai. Sedangkan wali kelas, hanya dapat mencetak raport. Berbeda dengan kedua hak akses diatas, admin dapat mengakses dan mengelola master data, seperti data siswa, guru, mata pelajaran dan lain-lain.

b. Desain.

Dalam proses ini database yang digunakan adalah MySQL, tentu saja sebelum membuat database penulis membuat rancangan database dengan menggunakan ERD dan LRS. Dan interface yang akan dibuat tentunya user friendly agar para pengguna terutama staf pengajar atau guru yang sudah paruh baya akan dengan mudahnya menggunakan sistem yang penulis buat.

\section{c. Code Generation}

Bahasa pemrograman yang akan digunakan adalah php, html, css dan javascript.

d. Testing

Pengujian fokus kepada perangkat lunak secara logic dan fungsional dan memastikan bahwa semua bagian sudah diuji untuk meminimalisir error dan keluaran harus sesuai dengan menggunakan BlackBox Testing.

e. Support

Dalam hal ini tentu saja penulis akan kritik dan saran dari para user yang menggunakan sistem ini, dimana setiap sistem tidak ada yang sempurna dan pasti membutuhkan perkembangan maupun perubahan demi sempurnanya sistem ini dikemudian hari. Agar user semakin nyaman menggunakan sistem ini.

\section{HASIL DAN PEMBAHASAN}

\section{Analisa Kebutuhan}

Berdasarkan proses bisnis berjalan pada MI Darul Muta'allimien, maka tahapan berikutnya adalah membuat aplikasi berbasis web. Berikut adalah analisa kebutuhan, sebagai berikut :

a. Admin, dapat melakukan Login, kemudian mengakses Halaman Utama. Pada Halaman Utama, Admin dapat mengelola Data Guru, Data Siswa, Data Mata Pelajaran, Data Semester, Data Akademik, Data Sikap, dan Data Tahun Berjalan

b. Guru, dapat melakukan Login, kemudian mengakses Halaman Utama. Pada Halaman Utama, Guru dapat mengelola Nilai Mata Pelajaran.

c. Wali Kelas, dapat melakukan Login, kemudian Halaman Utama. Wali Kelas dapat mengelola Nilai Sikap, Nila Absen dan Ekskul, dan mencetak Raport. 


\section{Use Case Diagram}

Menurut Mubin dalam (Putra, 2018), "Use Case diagram dapat menetukan pengguna potensial dan bagaimana mereka bereaksi terhadap aktivitas dan aliran proses dalam aplikasi berbasis web". Dalam Use Case diagram terdapat aktor yang akan menjalankan aktifitasnya dalam program atau aplikasi yang akan dibuat.

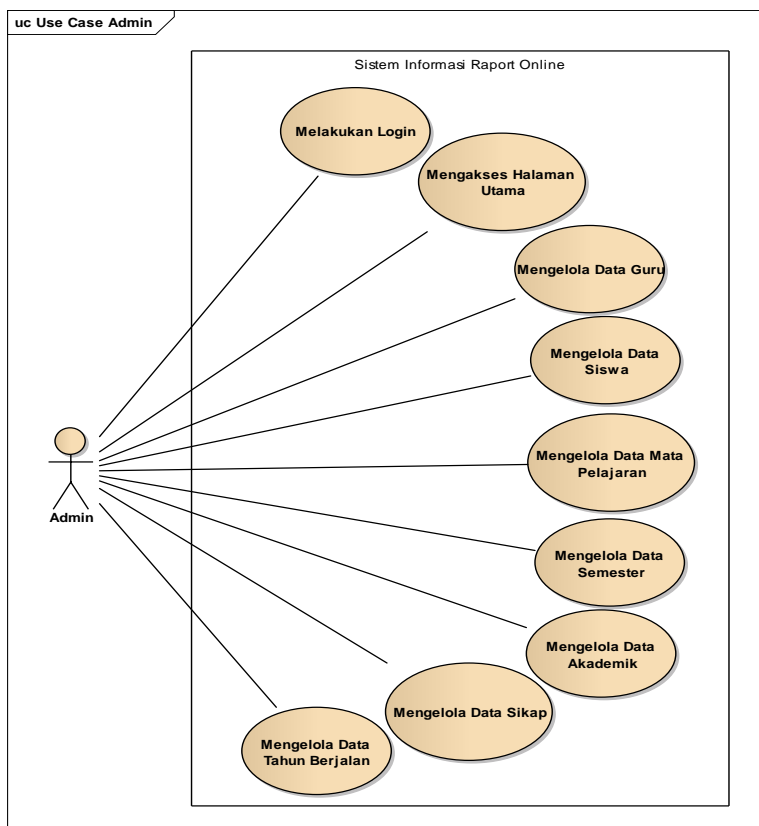

Sumber: (Wijasty, Utami, Priyono, \& Yunandar, 2019)

\section{Gambar 1. Use Case Diagram Admin}

Gambar 1 merupakan penjelasan hak akses Admin pada Aplikasi Sistem Informasi Raport Online, dimana terlihat bahwa Admin dapat mengakses ke semua master data.

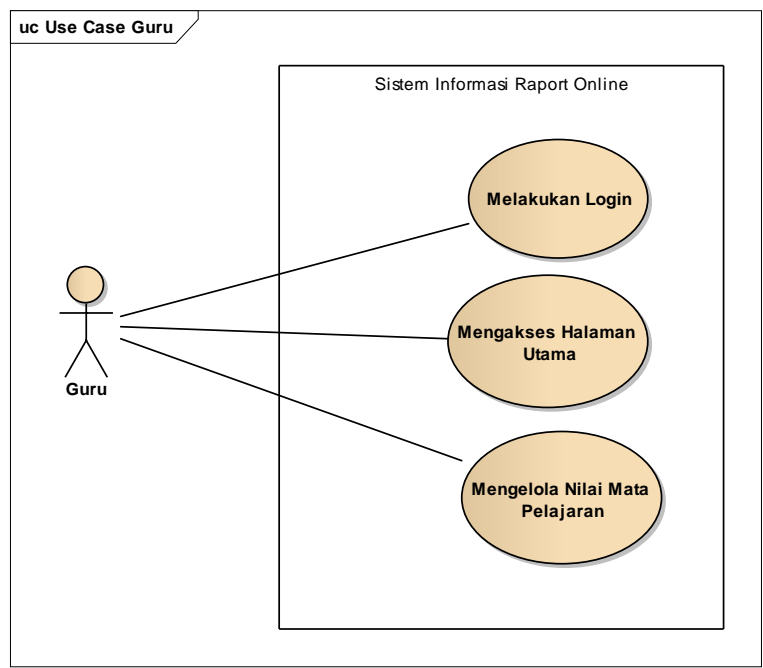

Sumber: (Wijasty et al., 2019)

Gambar 2. Use Case Diagram Guru
Gambar 2 merupakan penjelasan hak akses Guru pada Aplikasi Sistem Informasi Raport Online, dimana terlihat bahwa Guru hanya dapat mengelola data nilai mata pelajaran siswa.

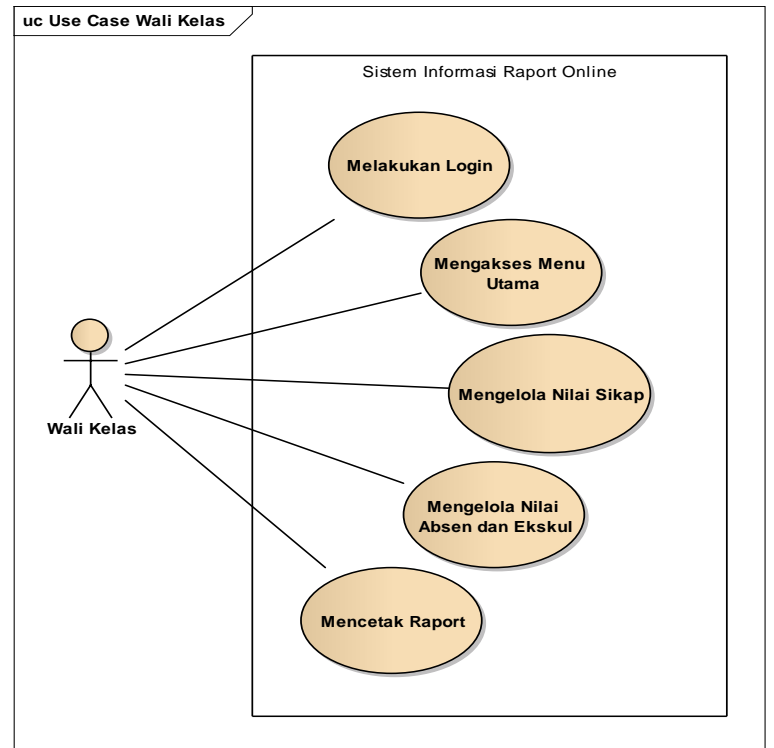

Sumber: (Wijasty et al., 2019)

Gambar 3. Use Case Diagram Wali Kelas

Gambar 3 merupakan penjelasan hak akses Wali Kelas pada Aplikasi Sistem Informasi Raport Online, dimana terlihat bahwa Wali Kelas memiliki hak untuk mengelola nilai sikap, absen dan ekskul. Wali Kelas juga dapat mencetak raport siswa.

\section{Activity Diagram}

Activity Diagram adalah salah satu cara untuk memodelkan event-event yang terjadi dalam suatu use case (Mahdiana, 2016)

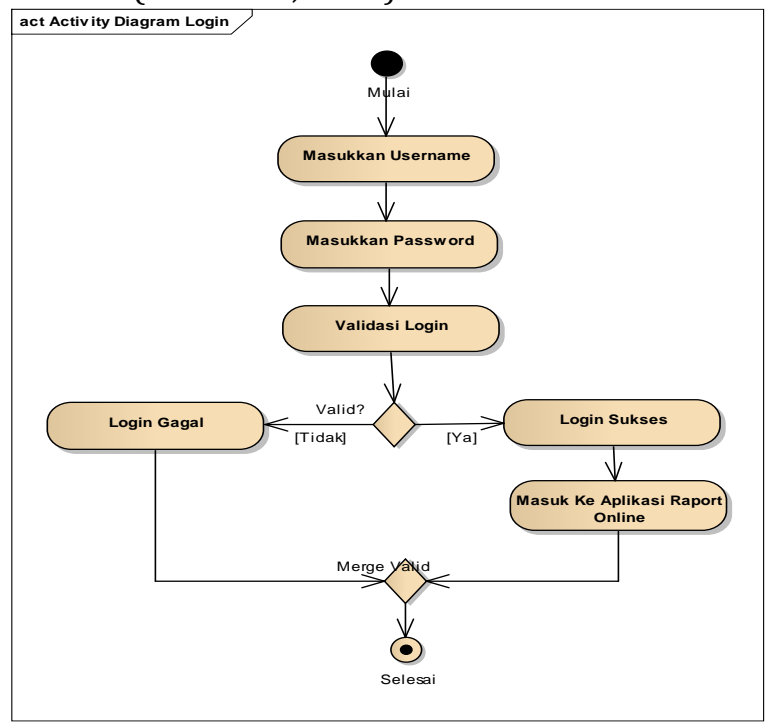

Sumber: (Wijasty et al., 2019)

Gambar 4. Activity Diagram Halaman Login 
Gambar 4 merupakan aktivitas yang dilakukan oleh pengguna, baik Admin, Guru ataupun Wali Kelas. Pengguna melakukan login ke Aplikasi Sistem Informasi Raport Online dengan cara memasukkan username, kemudian diikuti dengan memasukkan password. Klik Login, maka sistem akan melakukan validasi. Jika data valid atau benar, maka akan masuk kedalam sistem. Jika sebaliknya, data tidak valid atau tidak benar, maka login dianggap gagal.

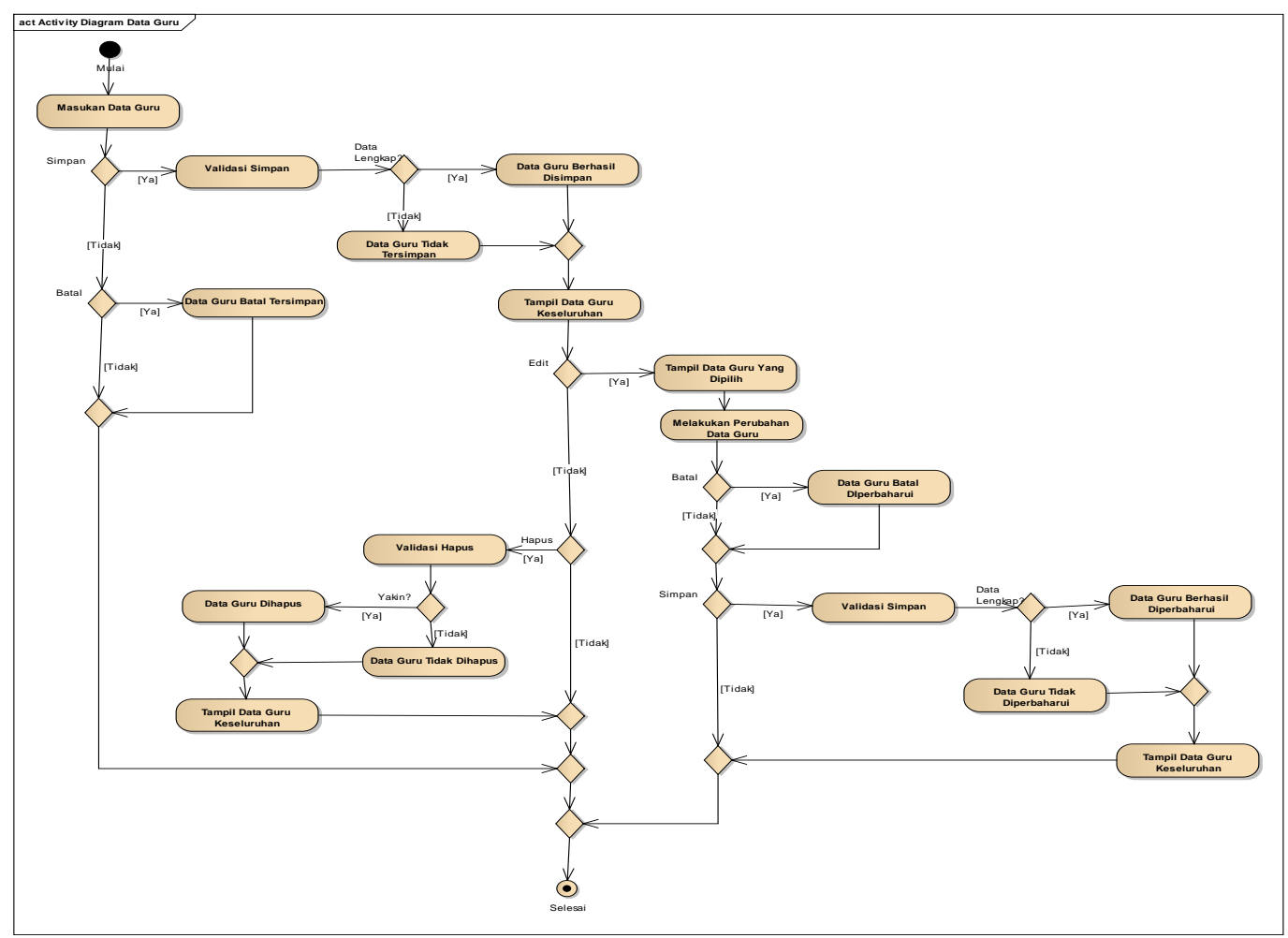

Sumber: (Wijasty et al., 2019)

Gambar 5. Activity Diagram Data Guru

Gambar 5 merupakan aktivitas yang dilakukan yang terjadi apabila pengguna mengelola data guru. Pengguna harus memasukkan data guru terlebih dahulu, jika data belum lengkap, maka data tidak bisa tersimpan. Sementara itu, jika data sudah lengkap, data bisa tersimpan atau dibatalkan. Saat data guru tampil secara keseluruhan, pengguna dapat melakukan perubahan atau menghapus data guru.

\section{Sequence Diagram}

Menurut (Mahdiana, 2016), Sequence diagram menggambarkan interaksi antar obyek di dalam dan di sekitar sistem (termasuk pengguna, display dan sebagainya) berupa message yang digambarkan terhadap waktu. Sequence diagram terdiri atas dimensi vertikal (waktu) dan dimensi horizontal (obyek- obyek yang terkait).

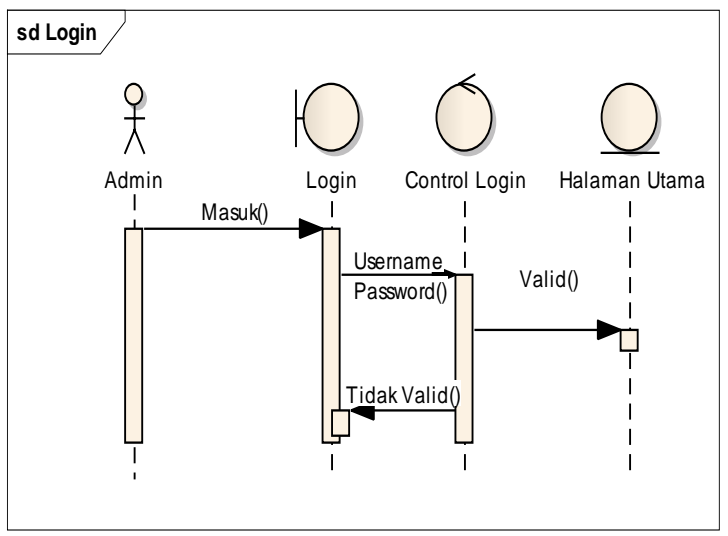

Sumber: (Wijasty et al., 2019)

Gambar 6. Sequence Diagram Login

Gambar 6 adalah penjelasan sistem login pada Aplikasi Sistem Informasi Raport Online berbentuk Sequence Diagram, dimana pengguna yang melakukan login, harus memasukkan username dan password terlebih dahulu. Jika valid, maka akan tampil halaman utama. Jika tidak valid, maka harus melakukan login ulang. 
sd Sequence Data Siswa

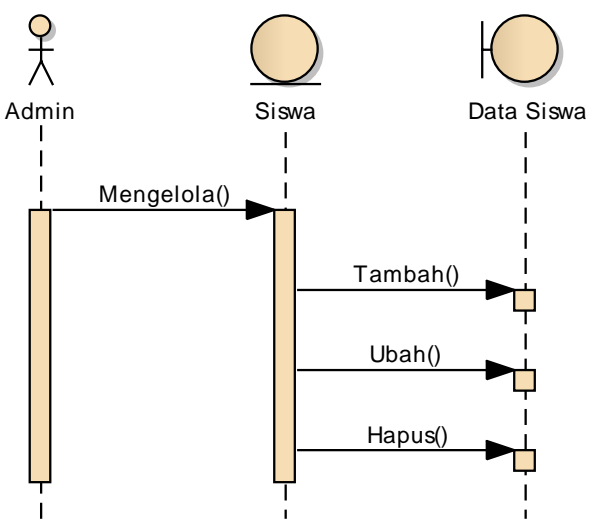

Sumber: (Wijasty et al., 2019)

Gambar 7. Sequence Diagram Data Siswa

Gambar 7 adalah penjelasan salah satu master data, yakni data siswa. Dalam pengelolaan data siswa ini, pengguna bisa menambah, mengubah, dan menghapus data siswa.

\section{Class Diagram}

Class Diagram merupakan diagram yang menunjukan class-class yang ada disistem dan hubungannya secara logic. (Novita \& Sari, 2015). Class Diagram pada aplikasi raport online tercantum pada gambar 8 .

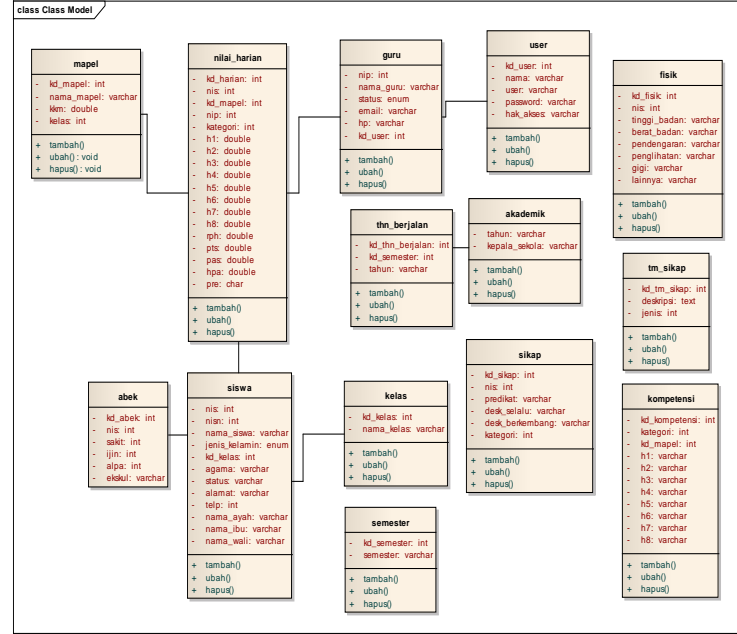

Sumber: (Wijasty et al., 2019)

Gambar 8. Class Diagram Aplikasi Sistem Informasi Raport Online

\section{Entity Relationship Diagram (ERD)}

Menurut Simarmata dalam (Fridayanthie \& Mahdiati, 2016), "Entity RelationShip Diagram (ERD) adalah alat pemodelan data utama dan akan mambantu mengorganisasi data dalam suatu proyek ke dalam entitas-entitas dan menentukan hubungan antar entitas"

Gambar 12 merupakan tampilan dari Entity Relationship Diagram (ERD) pada aplikasi Sistem Informasi Raport Online dimana disetiap tabel memiliki relasi tersendiri.

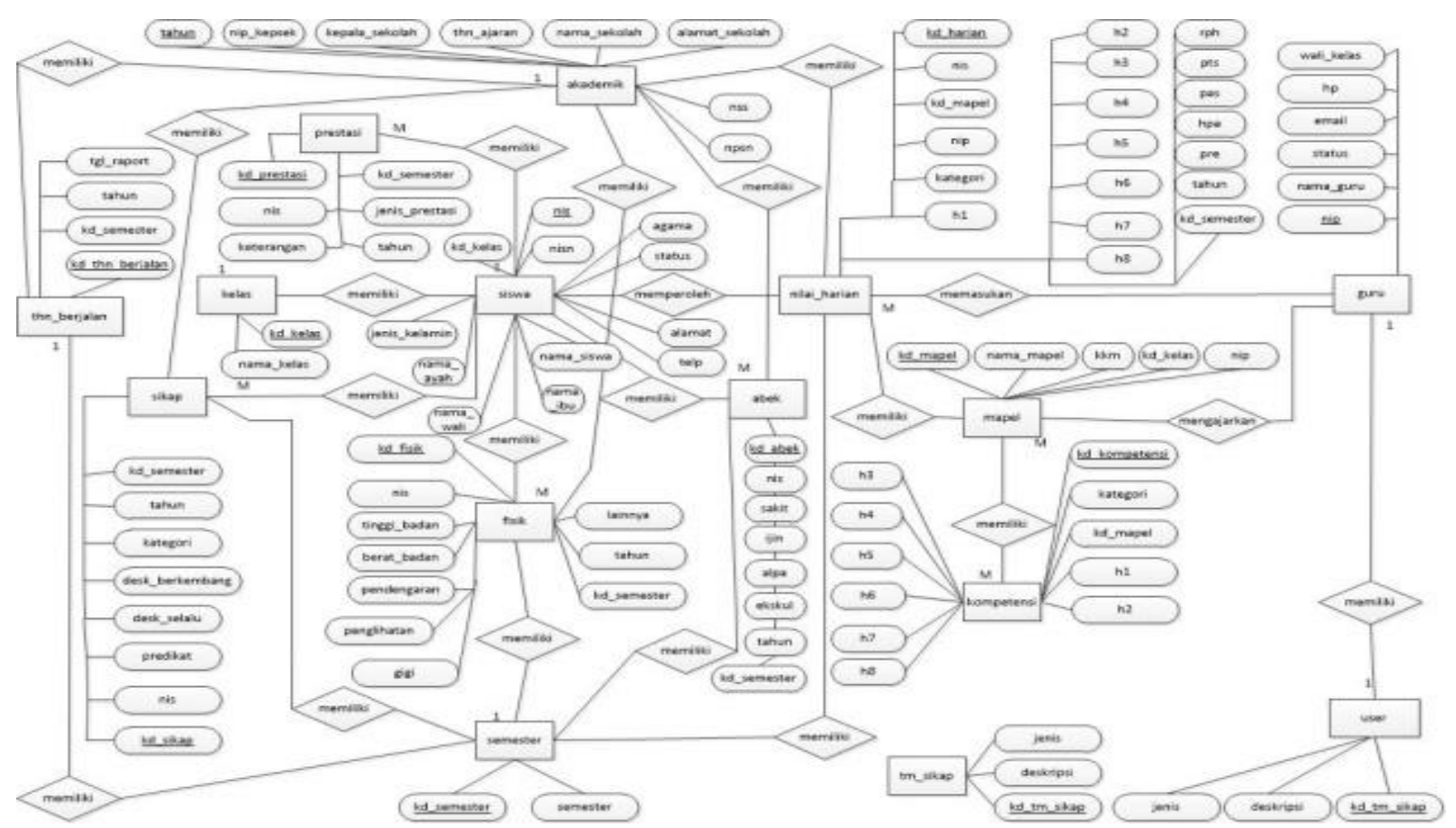

Sumber: (Wijasty et al., 2019)

Gambar 9. Entity Relationship Diagram Aplikasi Sistem Informasi Raport Online 
Aplikasi Sistem Informasi Raport Online memiliki 14 tabel yang dimana semua tabel saling relasi. Setiap tabel saling terhubung, dan memiliki kardinalitas tersendiri, yakni One to One, atau One to Many (Gambar 9).

\section{User Interface}

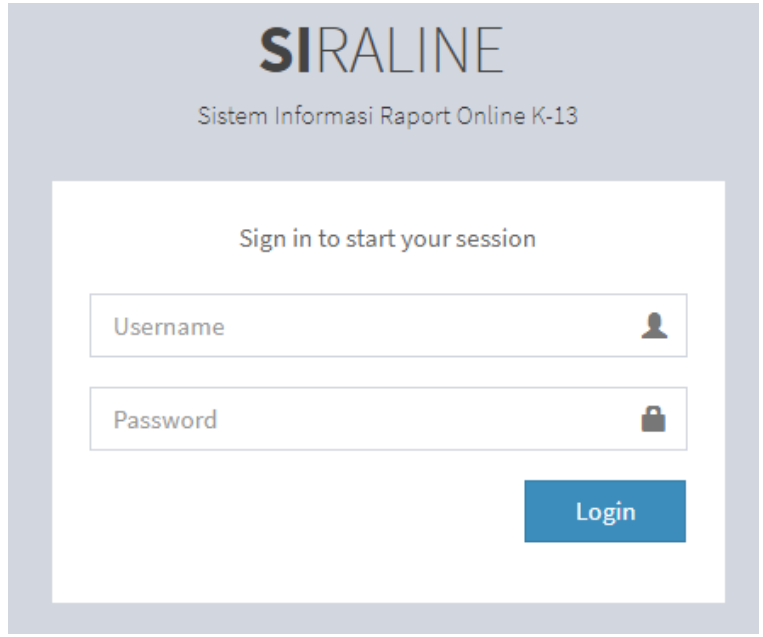

Sumber: (Wijasty et al., 2019)

Gambar 10. User Interface Login

Gambar 10 adalah tampilan dari aplikasi untuk login pengguna. Dalam tampilan terlihat, pengguna harus memasukkan username dan password, kemudian klik button Login.

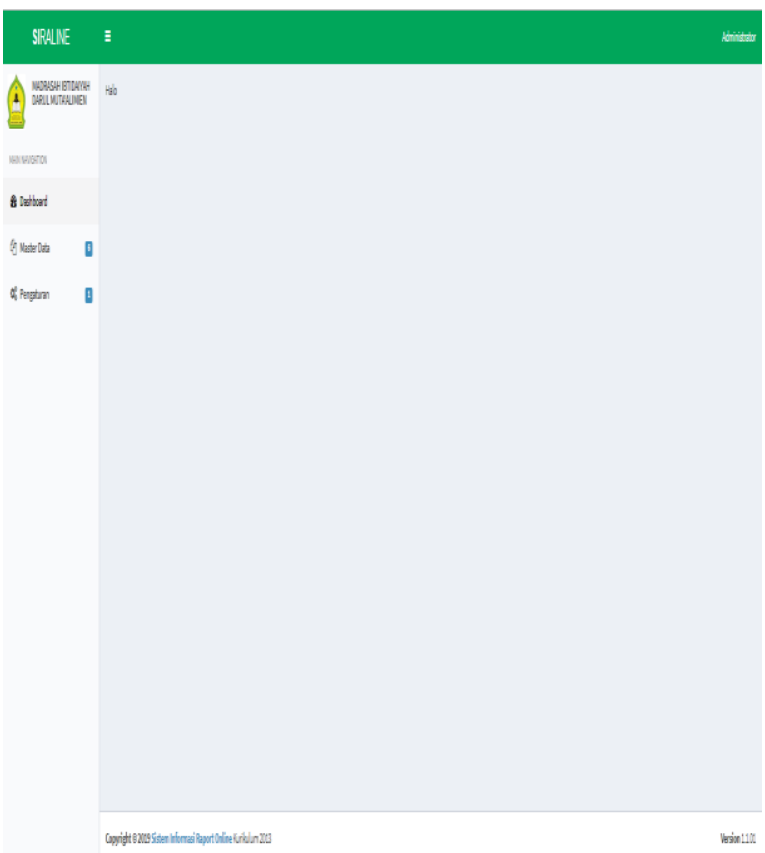

Sumber: (Wijasty et al., 2019)

Gambar 11. User Interface Menu Utama
Gambar 11 adalah tampilan dari aplikasi, yakni menu utama Admin. Jika Wali Kelas sudah menerima pengolahan nilai dari Guru, maka dilanjutkan oleh Wali Kelas untuk mengelola nilai absensi dan ekskul. Saat semua nilai sudah dimasukkan dan diolah, maka Wali Kelas akan mencetak sebuah raport siswa. Bentuk cetakan raport siswa terlihat pada gambar 12 .

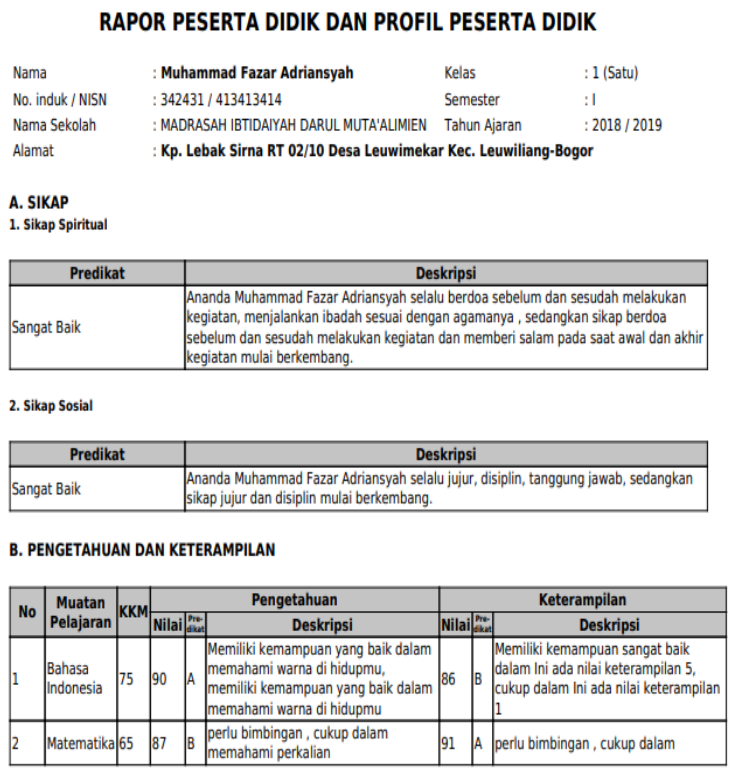

Tabel Interval Predikat Berdasarkan KKM

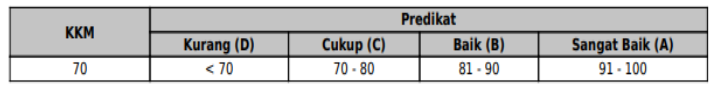

C. EKSTRAKURIKULER

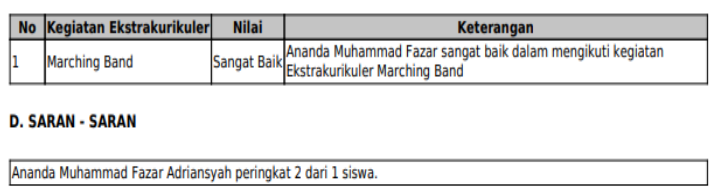

E. TINGGI DAN BERAT BADAN

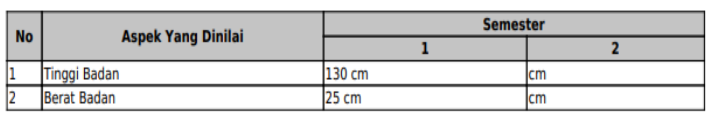

F. KONDISI KESEHATAN

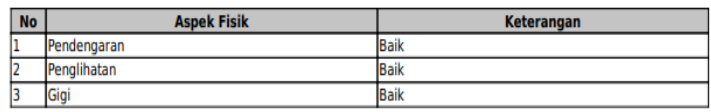

Sumber: (Wijasty et al., 2019)

Gambar 12. User Interface Raport

\section{KESIMPULAN}

Aplikasi sistem informasi raport online kurikulum 2013 adalah cara baru proses pengolahan nilai. Aplikasi sistem informasi raport online kurikulum 2013 merupakan dasar dan konsekuensi logis dari perkembanngan teknologi informasi dan komunikasi. 
Aplikasi sistem informasi raport online kurikulum 2013 sangat berguna bagi para guru yang kesulitan dalam mengolah nilai kurikulum 2013. Aplikasi sistem informasi raport online kurikulum 2013 ini membuka peluang bagi semua guru untuk mengolah nilai dimana pun dan kapanpun. Sehingga waktu dan tempat bukan sudah hambatan lagi bagi para guru ataupun wali kelas. Tenaga yang dibutuhkan untuk memproduksi 1 (satu) nilai lebih efisien daripada menggunakan cara manual.

Aplikasi sistem informasi raport online kurikulum 2013 juga dapat menghemat biaya kertas dan biaya lainnya, sehingga lebih terjangkau dibandingkan mengolah nilai secara fisik atau tertulis.

\section{REFERENSI}

Budiyarto, N. R., \& Rochmawati, N. (2016). Sistem Informasi Raport Online SMA Negeri 1 Krembung. Manajemen Informatika, 6(1), 108-116. https://doi.org/10.5151/cidi2017060

Fridayanthie, E. W., \& Mahdiati, T. (2016). Rancang Bangun Sistem Informasi Permintaan ATK Berbasis Intranet (Studi Kasus: Kejaksaan Negeri Rangkasbitung). Khatulistiwa Informatika, 4(2), 10 https://doi.org/10.5151/cidi2017-060

Mahdiana, D. (2016). Analisa dan Rancangan Sistem Informasi Pengadaan Barang dengan Metodologi Berorientasi Obyek: Studi Kasus PT. Liga Indonesia. Telematika MKOM, 3(2), 36-43.

Muhson, A. (2010). Pengembangan Media Pembelajaran Berbasis Teknologi Informasi. Pendidikan Akuntansi Indonesia, VIII(2), 1-10.

Novita, R., \& Sari, N. (2015). Sistem Informasi Penjualan Pupuk Berbasis E-Commerce. Teknoif, 3(2), 1-6.

Putra, E. A. (2018). Analisa Dan Perancangan Sistem Pelaporan Kinerja Pegawai Menggunakan Work System Framework Dengan Pemodelan UML. INTECOMS: Journal of Information Technology and Computer Science, 1(2), 151-158. https://doi.org/10.31539/intecoms.v1i2.296

Sari, H. P., \& Muhartini, R. (2017). Sistem Aplikasi Pengolahan Nilai Raport SDN Tanjunganom 2 Kecamatan Tanjunganom Nganjuk. Antivirus : Jurnal Ilmiah Teknik Informatika, 11(1), 65-
80. https://doi.org/10.35457/antivirus.v11i1.19 9

Sari, \& Saputra, E. H. (2014). Sistem Informasi Raport Berbasis Web Di SMPN 4 Temanggung. Data Manajemen Dan Teknologi Informasi (DASI), 15(2), 24.

Wisarja, I. K., \& Sudarsana, I. K. (2017). Refleksi Kritis Ideologi Pendidikan Konservatisme Dan Libralisme Menuju Paradigma Baru Pendidikan. Journal of Education Research and Evaluation, 1(4), 283. https://doi.org/10.23887/jere.v1i4.11925 
